\title{
Biological treatment of a contaminated gaseous emission from a paint and varnish plant - from laboratory studies to pilot-scale operation
}

\author{
Filipe SC Bastos, ${ }^{1}$ Paula ML Castro ${ }^{2 *}$ and Ruben Ferreira Jorge ${ }^{1,2}$ \\ ${ }^{1}$ Escola Superior de Biotecnologia - Universidade Católica Portuguesa, R Dr António Bernardino de Almeida, 4200-072 Porto, Portugal \\ ${ }^{2}$ SIA - Sociedade de Inovação Ambiental, Lda, CEBI - Centro Empresarial de Biotecnologia, R Dr António Bernardino de Almeida, \\ 4200-072 Porto, Portugal
}

\begin{abstract}
A Vapour-Phase Bioreactor (VPB), namely a biotrickling filter, was scaled-up and operated insitu for the treatment of gaseous emissions from a paint and varnish industrial plant. A microbial culture able to degrade the target compounds was enriched and a laboratory-scale VPB was established in order to evaluate the treatment's performance. The VPB presented removal efficiencies higher than $90 \%$ when exposed to Organic Loads (OL) of $c a 50 \mathrm{~g} \mathrm{~h}^{-1} \mathrm{~m}^{-3}$ of reactor. The VPB was exposed to dynamic conditions often found in-situ (eg night and weekend shutdown periods) and showed a fast capacity to recover, with and without mineral medium recirculation. After a prolonged interruption period (10 months), the VPB was not able to cope with OL of $c a 25 \mathrm{~g} \mathrm{~h}^{-1} \mathrm{~m}^{-3}$ of reactor and re-inoculation was required in order to recover the treatment performance. The VPB also showed limited treatment when exposed to higher OL (ca $500 \mathrm{~g} \mathrm{~h}^{-1} \mathrm{~m}^{-3}$ of reactor). The VPB was then scaled-up and a $3 \mathrm{~m}^{3} \mathrm{VPB}$ was operated in-situ, showing removal efficiencies higher than $50 \%$ when exposed to an OL of $c 5 \mathrm{~g} \mathrm{~h}^{-1} \mathrm{~m}^{-3}$ of reactor, thus complying with current legal demands. The addition of a maintenance feed was shown to be a useful tool for VPB pilot-scale operation when shutdown periods occurred. A factorial design of experiments was carried out, which allowed reduction to one-tenth of the initial supply of the main mineral medium constituents, namely phosphate buffer, ammonium and magnesium salts, and also elimination of the metal supplement. Overall, the VPBs were shown to be robust equipment, being able to respond actively to dynamic treatment scenarios, particularly night and weekend shutdown periods.
\end{abstract}

Keywords: biological treatment; vapour-phase bioreactor; biofilm; VOCs; paint and varnish

\section{INTRODUCTION}

Vapour-Phase Bioreactors (VPBs) have been classified as Best Available Technologies for air pollution control from various chemical industries. ${ }^{1}$ However, VPBs are not found worldwide and are mainly focused in north and central Europe. ${ }^{2}$ VPBs have been successfully applied at laboratory-scale in the treatment of a wide variety of Volatile Organic Compounds (VOCs), both aliphatics $^{3,4}$ and aromatics. ${ }^{5-7}$

Selection of appropriate microbial cultures is the first problem to solve regarding the wider implementation of VPBs, and such selection procedures can last for several months. ${ }^{8}$ Suitable microbial cultures are often derived from polluted sites. Isolation of the specialised microbial culture is often preceded by an acclimation period, generally accomplished by classical cultivation techniques: batch and continuous enrichment methods. ${ }^{9}$ A successful enrichment process will result in the isolation of microbial cultures able to degrade the target pollutant. In-situ inoculation of the enriched microbial culture in bioreactors is frequently successful, as the conditions at such engineered systems can be altered or optimised to promote the multiplication and activity of the inoculated species - in contrast with field sites. ${ }^{10}$

For successful scale-up, treatment conditions found in-situ should be mimicked at laboratory-scale. ${ }^{10}$ Investigations into dynamic treatment scenarios, including treatment of mixtures of pollutants; ${ }^{11-13}$ transient concentrations of pollutants; ${ }^{4,14-17}$ starvation periods ${ }^{3,4,18-20}$ and pulses of mixture of pollutants, ${ }^{19,20}$ have been carried out. VPBs have been

* Correspondence to: Paula ML Castro, Escola Superior de Biotecnologia, Universidade Católica Portuguesa, R Dr António Bernardino de Almeida, 4200-072 Porto, Portugal

E-mail: plc@esb.ucp.pt 
found to have a limited application when considering highly loaded effluents. ${ }^{1,2}$ Inability to treat highly concentrated loads and/or extreme fluctuations in loading conditions can be overcome by new design solutions ${ }^{21}$ and different operating strategies, ${ }^{22}$ such as biphasic reactors $^{21}$ or directional switching operational mode. ${ }^{22}$

The objective of this study was to develop a pilotscale VPB able to treat a gaseous emission from a paint and varnish plant. The research carried out involved enrichment of microbial cultures, laboratory studies to validate the treatment process and mimicking of insitu conditions, optimisation of treatment operation, scaling-up of the trickle-bed filter, and implementation and in-situ operation of the pilot-scale VPB. The effects of variable inlet organic loading, overnight and weekend periodical shutdowns and of starvation periods on the overall treatment performance of the VPB were investigated.

\section{EXPERIMENTAL}

\subsection{Soil and isolating media}

Soil samples were collected from a contaminated site in the vicinity of a paint and varnish plant in northern Portugal. Samples were well-mixed and undesirable materials (stones, garbage, roots, etc) removed. Samples of this mixture were inoculated in mineral medium (MM) containing $50 \mathrm{mg} \mathrm{dm}^{-3}$ of solvent as the sole carbon and energy source. The exact solvent composition, hereinafter referred to as SOLV, was not revealed for imposed reasons of business secrecy. Information released on the SOLV stated it as being a liquid mixture of eight different aliphatic organic compounds, mainly ketones and aldehydes, with a density of $0.9 \mathrm{~kg} \mathrm{dm}^{-3}$. The MM used in these experiments contained the following compounds per $\mathrm{dm}^{3}: \mathrm{Na}_{2} \mathrm{HPO}_{4} \cdot 2 \mathrm{H}_{2} \mathrm{O}$ $(2.67 \mathrm{~g}) ; \mathrm{KH}_{2} \mathrm{PO}_{4}(1.4 \mathrm{~g}) ; \mathrm{MgSO}_{4} \cdot 7 \mathrm{H}_{2} \mathrm{O}(0.8 \mathrm{~g})$; $\left(\mathrm{NH}_{4}\right)_{2} \mathrm{SO}_{4} \quad(0.5 \mathrm{~g}) ;$ and $10 \mathrm{~cm}^{3}$ of a metal supplement solution. The metal supplement solution contained the following compounds per $\mathrm{dm}^{3}: \mathrm{NaOH}$ $(2.0 \mathrm{~g}) ; \quad \mathrm{Na}_{2}$ EDTA $2 \mathrm{H}_{2} \mathrm{O} \quad(12 \mathrm{~g}) ; \quad \mathrm{FeSO}_{4} \cdot 7 \mathrm{H}_{2} \mathrm{O}$, $(2 \mathrm{~g}) ; \mathrm{CaCl}_{2}(1 \mathrm{~g}) ; \mathrm{Na}_{2} \mathrm{SO}_{4}(10 \mathrm{~g}) ; \mathrm{ZnSO}_{4} \cdot 7 \mathrm{H}_{2} \mathrm{O}$ $(0.4 \mathrm{~g}) ; \mathrm{MnSO}_{4} \cdot 4 \mathrm{H}_{2} \mathrm{O}(0.4 \mathrm{~g}) ; \mathrm{CuSO}_{4} \cdot 5 \mathrm{H}_{2} \mathrm{O}(0.1 \mathrm{~g})$; $\mathrm{Na}_{2} \mathrm{MnO}_{4} \cdot 2 \mathrm{H}_{2} \mathrm{O} \quad(0.1 \mathrm{~g}) ; \quad \mathrm{H}_{2} \mathrm{SO}_{4}$ concentrated $\left(0.5 \mathrm{~cm}^{3}\right)$, the latter added to adjust the solution $\mathrm{pH}$ to 7. Enriched microbial cultures were maintained on slopes of nutrient agar at $5^{\circ} \mathrm{C}$ and subcultured when required, and were also frozen in $20 \%$ glycerol $(\mathrm{v} / \mathrm{v})$ and stored at $-70^{\circ} \mathrm{C}$ for further studies. During the experiments non-sterile conditions were maintained.

\subsection{VPB operation at laboratory-scale}

A VPB was operated for treatment of a SOLVcontaminated gaseous effluent. The experimental setup is schematically shown in Fig 1 . The biotrickling filter consisted of an $80 \mathrm{~cm}$ high and $9 \mathrm{~cm}$ internal diameter cylindrical stainless-steel column. A perforated stainless-steel plate was placed at the bottom of the column to allow for a better distribution of the gaseous
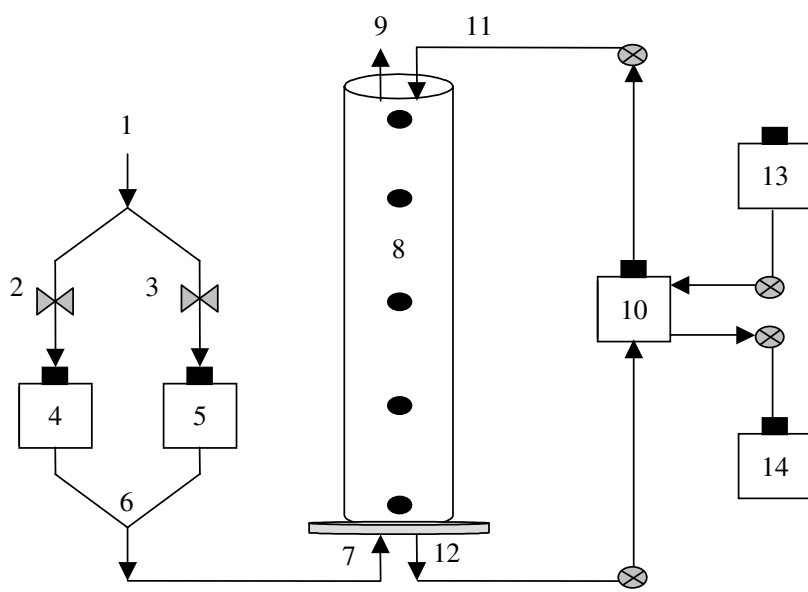

Figure 1. Schematic representation of the biotrickling reactor at laboratory-scale. 1-Pressurised air; 2,3-gaseous mass-flow controllers; 4,5-saturation vessels; 6 -mixture point; 7 -inlet gas; 8 -VPB; 9 - outlet gas; 10 - recirculation vessel; 11 - mineral medium inlet; 12 - mineral medium outlet; 13 - mineral medium feed; $14-$ mineral medium waste.

effluent through the column. A water nozzle was used to disperse the recirculating MM homogeneously. The reactor column also contained three additional sampling ports, which were located along the filter bed at 20,40 and $60 \mathrm{~cm}$ from the bottom. The reactor was filled with a $5 \mathrm{~cm}$ sand layer at the bottom and the rest of the column height was filled with PVC pall-rings.

For biofilm establishment, MM containing $200 \mathrm{mg}$ $\mathrm{dm}^{-3}$ SOLV inoculated with a microbial culture able to degrade the SOLV constituents was continuously recirculated through the biotrickling filter for 3 days, at a flow rate of $50 \mathrm{~cm}^{3} \mathrm{~h}^{-1}$. During bioreactor operation, the gaseous effluent was continuously fed to the reactor in a countercurrent mode with the liquid flow. The required SOLV gaseous inlet concentration was achieved by the control mixture of a SOLV-laden stream with a water-laden stream. By changing the ratio of the gaseous-laden streams, different SOLV inlet gaseous concentrations could be obtained. The recirculation flow was initially set at $250 \mathrm{dm}^{3} \mathrm{~h}^{-1}$ and $M M$ was continuously fed at $50 \mathrm{~cm}^{3} \mathrm{~h}^{-1}$. The Empty Bed Residence Time (EBRT) for gas was maintained at $2.5 \mathrm{~min}$ during the experiments. Gaseous samples were periodically withdrawn from the inlet and outlet sampling points, and occasionally from the centre of the other reactor sampling points, allowing for the characterisation of the gaseous effluent concentration through the reactor column height (at inlet-0\%, $25 \%, 50 \%, 75 \%$ and outlet $-100 \%$, of the column height). Removal Efficiencies (RE, \%) as well as the Organic Load (OL, $\mathrm{gh}^{-1} \mathrm{~m}^{-3}$ of reactor) and the reactor Elimination Capacity $\left(\mathrm{EC}, \mathrm{g} \mathrm{h}^{-1} \mathrm{~m}^{-3}\right.$ of reactor) were determined.

Operating conditions found in-situ, such as overnight and weekend shutdown periods, were investigated, as the plant under study operated $12 \mathrm{~h} /$ day and 5 days/week. Longer starvation periods ( $1-2$ weeks) were also investigated, mimicking periodical plant shutdowns. At laboratory-scale, experiments were 
at least repeated twice. A long interruption period (10 months) was also tested with the objective of evaluating the recovery capacity of a VPB.

\subsection{VPB operation at pilot-scale}

The pilot unit consisted of a closed $3 \mathrm{~m}^{3}$ stainlesssteel column filled with pall-rings as growth support material. The $\mathrm{MM}$ was stored in a closed $1 \mathrm{~m}^{3}$ PVC tank and was recirculated between both units, always fed from the top of the trickle-bed column, in countercurrent mode with the gas effluent. Water levels controlled the exchange flows between both tanks in order to avoid MM accumulation in the trickle-bed column. The operational conditions were similar to those investigated at laboratory-scale (eg EBRT of $2.5 \mathrm{~min}$ ). In order to better disperse the gaseous effluent through the bed column, a sparger was introduced at the inlet gas stream. Gaseous samples for VPB monitoring were collected using Teflon air-sample sealed $1 \mathrm{dm}^{3}$ bags. Microbial inocula for VPB operation at pilot-scale were prepared in $5 \mathrm{dm}^{3}$ reactors operated in a fed-batch mode, to which known amounts of SOLV were continually fed. Biomass was then concentrated by successive centrifugations.

\subsection{Analytical methods}

Both gaseous and liquid samples were analysed for quantification of organic compounds using a gas chromatograph (Hewlett Packard 5890, UK) equipped with a flame-ionisation detector. A $50 \mathrm{~m}$ long packed column (type Column CP-WAX 57CB, Varion, UK) with $0.25 \mathrm{~mm}$ inner diameter was used at a carrier gas (hydrogen:argon 50:50) flow rate of $8 \mathrm{~cm}^{3} \mathrm{~min}^{-1}$. The column was maintained at $80^{\circ} \mathrm{C}$. Gaseous samples of $1 \mathrm{~cm}^{3}$ were collected from the inand outlet-stream, as well as from three sample ports over the height of the reactor column. All samples were analysed at least twice. Calibration was performed weekly and since SOLV composition was unknown, the total area of the injected sample, composed of eight peaks, was considered. The recirculating media were also analysed for the presence of SOLV, as described elsewhere. ${ }^{19}$

All chemicals used in the preparation of the MM were obtained from $\mathrm{BDH}$ and were of AnalaR grade. All the organic solvents were obtained from Sigma.

\subsection{MM optimisation}

A full-scale factorial design of experiments was carried out in order to optimise MM composition, namely the metal supplement and the three major MM constituents: phosphates, ammonium salts and magnesium. Shake-flasks of $250 \mathrm{~cm}^{3}$ were inoculated with $5 \mathrm{~cm}^{3}$ of inoculum grown in $\mathrm{MM}$ containing $100 \mathrm{mg} \mathrm{dm}^{-3}$ SOLV. A factorial combination of the different salt concentrations was carried out using the value of the $M M$ as a high concentration and a tenth of the referred value as a low concentration, with and without addition of metal supplement. Microbial growth was monitored and specific growth rate and maximum biomass concentration were evaluated. The water used for MM preparation was collected at the industrial site. Experiments were repeated at least twice. Statistical significance of results was evaluated by comparison of mean squares ( $F$-test).

\section{RESULTS AND DISCUSSION}

\subsection{Microbial enrichment}

Microbial cultures able to degrade the solvent compounds were successfully enriched from the soil samples using batch methods. The enrichment process took approximately 2 weeks. Degradation was confirmed on batch assays by GC analysis.

\subsection{VPB operation at laboratory-scale}

The enriched microbial culture was inoculated into the VPB, which was initially operated in a closed mode to allow for biomass adaptation to the support growth material. The VPB was initially exposed to a gas effluent containing an OL of $12 \mathrm{~g} \mathrm{~h}^{-1} \mathrm{~m}^{-3}$ of reactor and stabilised at ca $90 \% \mathrm{RE}$ and $c a$ $12 \mathrm{~g} \mathrm{~h}^{-1} \mathrm{~m}^{-3}$ of reactor EC on day 8 (Fig $2(\mathrm{~A})$ ). The OL was then sequentially increased, up to a maximum of $48 \mathrm{~g} \mathrm{~h}^{-1} \mathrm{~m}^{-3}$ of reactor on day 13 . Despite the observed increase in the EC, the RE immediately decreased, reaching a minimum value of $49 \%$, suggesting that the reactor was not able to deal with such a high OL at that specific time period. After decreasing the OL (from day 16) to lower values (ca $17 \mathrm{~g} \mathrm{~h}^{-1} \mathrm{~m}^{-3}$ of reactor), the $\mathrm{RE}$ increased and stabilised at $80 \%$. The step increase in OL to $c a$ $30 \mathrm{~g} \mathrm{~h}^{-1} \mathrm{~m}^{-3}$ of reactor (day 22) was followed by a similar increase in RE to ca $87 \%$.

The VPB was then exposed to a 2-week starvation period mimicking a periodical plant shutdown (day 27). No MM was recirculated through the filter-bed column. At day 40, the VPB was exposed to an OL of $50 \mathrm{~g} \mathrm{~h}^{-1} \mathrm{~m}^{-3}$ of reactor. Initially, the VPB showed $25 \%$ RE. After $2 \mathrm{~h}$, the VPB recovered the previously observed high RE values (ca 90\%). The OL was further increased to $c a 60 \mathrm{~g} \mathrm{~h}^{-1} \mathrm{~m}^{-3}$ of reactor and the $\mathrm{RE}$ was maintained at high values. Aiming at the investigation of the operating regimes found in-situ, the OL was then step decreased, first to $45 \mathrm{~g} \mathrm{~h}^{-1} \mathrm{~m}^{-3}$ of reactor and then to $15 \mathrm{~g} \mathrm{~h}^{-1} \mathrm{~m}^{-3}$ of reactor. The RE was subsequentially decreased to $c a 60 \%$, suggesting that the reactor was under a diffusion-limited regime. ${ }^{13}$

The VPB was then exposed to another 2 weeks' starvation period (day 57), with no MM recirculation through the filter bed. Subsequently, the VPB was exposed to the previous OL $\left(c a 11 \mathrm{~g} \mathrm{~h}^{-1} \mathrm{~m}^{-3}\right.$ of reactor), and within 1 day the reactor recovered the RE values of $75 \%$. The VPB clogged on day 77 . Upon opening, a uniform biofilm distribution was found on the pall-rings' growth support material, with excessive biofilm found at the lower sections. No significant biofilm was observed on the support base sand section. During the experiments, residual suspended biomass concentrations and no trace of solvent compounds 


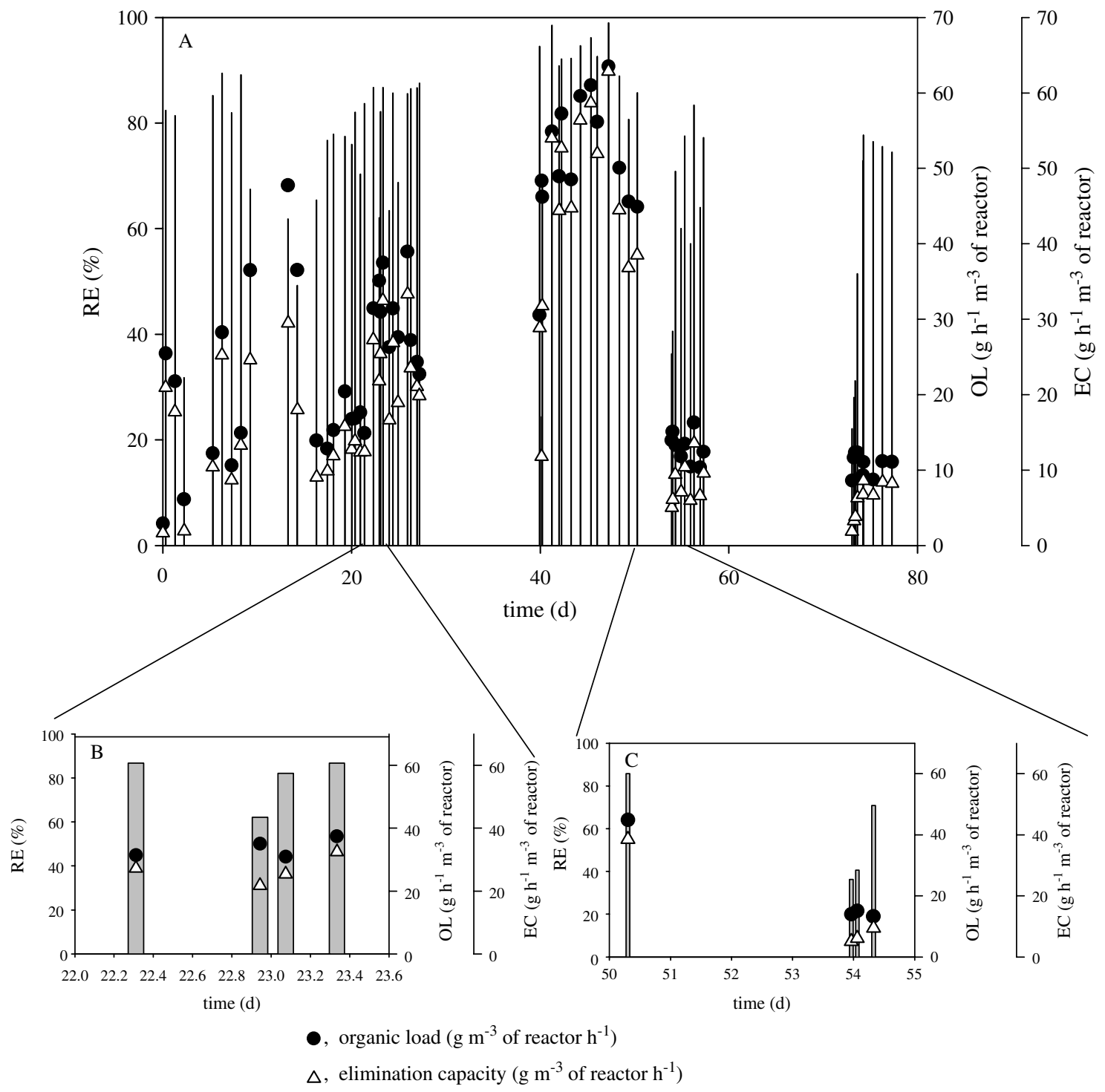

Figure 2. Removal efficiency (RE, \%, vertical bars) versus organic load $\left(\mathrm{g} \mathrm{m}^{-3}\right.$ of reactor $\left.\mathrm{h}^{-1}\right)$ and elimination capacity $\left(\mathrm{g} \mathrm{m}^{-3}\right.$ of reactor $\mathrm{h}^{-1}$ ) obtained during VPB operation at laboratory-scale $(A)$ and exposed to dynamic treatment scenarios of night $(B)$ and weekend $(C)$ shutdown periods.

were observed in the recirculation vessel (data not shown). Partial RE along the reactor column height was also characterised. In accordance with previous studies, ${ }^{23}$ the majority of the treatment $(>75 \%)$ predominated at the first half of the reactor height.

Night and weekend shutdown periods were also investigated (Fig 2(B and C)). After start-up, the reactor was perfectly capable of dealing with such treatment interruptions, with downtime minimised to low values as the reactor recovered maximum capacity within the first hour of operation. The effect of MM recirculation through the reactor filter-bed during these periods was also investigated and no significant difference was observed.

The results obtained advance the robustness of VPBs when exposed to dynamic treatment conditions, ie OL shifts and periodical short (night and weekend) and long (2 weeks) shutdown periods. Other studies have suggested that the robustness of biological treatment technologies when exposed to alternating treatment scenarios was due to microbial interactions. ${ }^{19,20,24}$ Microbial interactions may occur when some species can use cellular death material, extracellular polymeric substances secreted by other species, or intermediates of other degradation processes, as carbon sources. ${ }^{24}$ In this study, such interactions between different strains may have been responsible for maintaining the microbial culture active during the starvation periods. The low RE observed under low OL operating regimes suggests that particular emphasis should be given to masstransfer limitations due to the high vapour pressures of the majority of compounds present in the gaseous effluent.

\subsection{Prolonged treatment interruption}

Upon clogging, the VPB used in the laboratoryscale experiment was left untouched for the following 10 months. After such a long starvation period, the VPB was exposed to an OL of $c a 20 \mathrm{~g} \mathrm{~h}^{-1} \mathrm{~m}^{-3}$ of reactor (Fig 3). The VPB was not initially inoculated with previously enriched biomass in order to better 


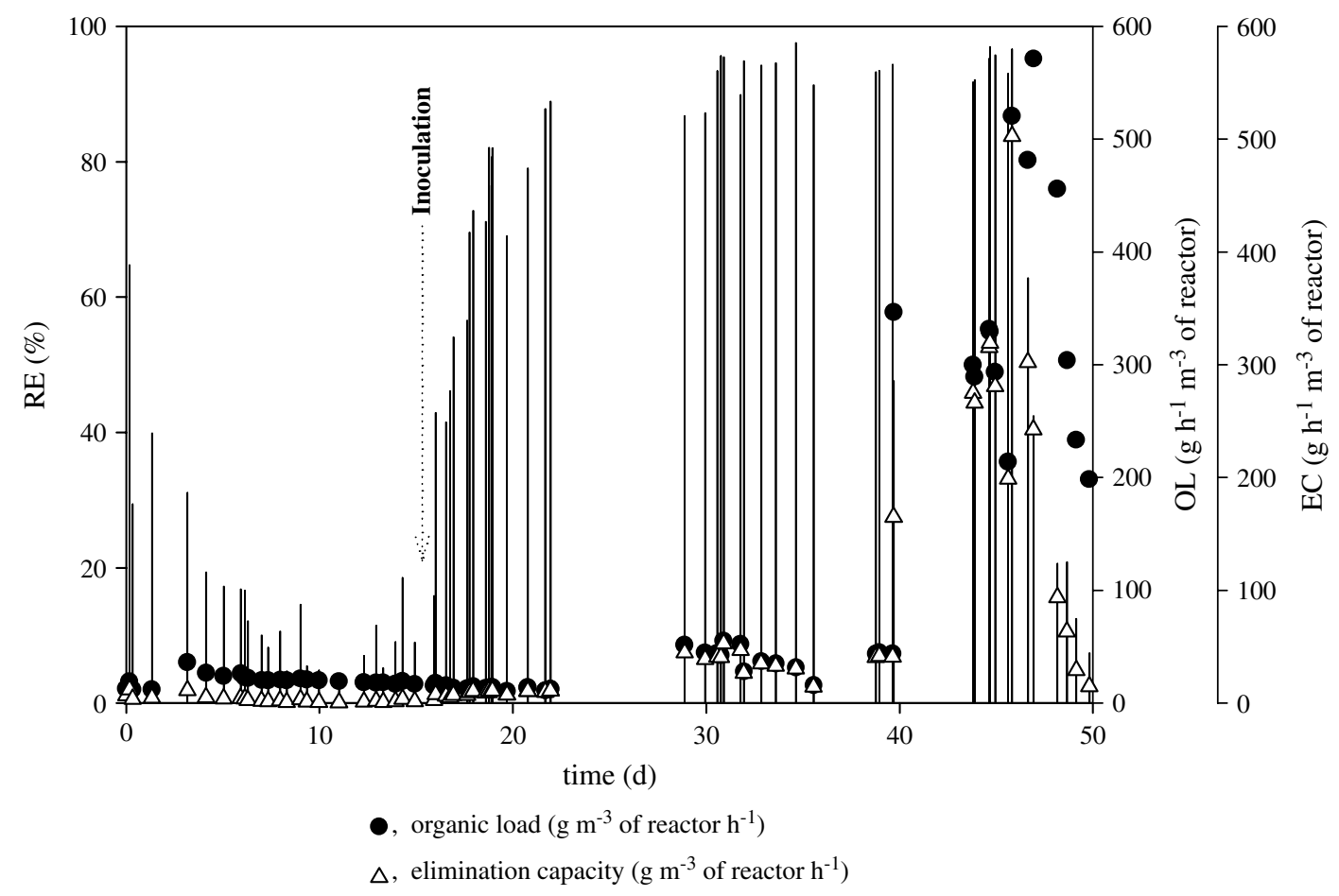

Figure 3. Removal efficiency (RE, \%, vertical bars) versus organic load ( $\mathrm{g} \mathrm{m}^{-3}$ of reactor $\mathrm{h}^{-1}$ ) and elimination capacity $\left(\mathrm{g} \mathrm{m}^{-3}\right.$ of reactor $\mathrm{h}^{-1}$ ) obtained during VPB operation at laboratory-scale after a prolonged interruption period of 10 months. Inoculation of the VPB with specialised microbial culture is also indicated.

characterise its capacity to recover. During the first 2 weeks of operation, the VPB showed poor RE, with the initial high values justified by adsorption phenomena to the organic matrix. No evidence of biological activity was observed, as shown from batch assays containing $100 \mathrm{mg} \mathrm{dm}^{-3}$ SOLV using inocula from the VPB recirculation vessel. In parallel, and using a fed-batch mode reactor, high concentrations of microbial culture grown in the target SOLV were prepared. On day 16 , an inoculum made of $400 \mathrm{~cm}^{3}$ with $c a 10 \mathrm{~g} \mathrm{dm}^{-3}$ of biomass was introduced into the VPB. After a few hours, an increase in the RE was observed, reaching $50 \%$. Within 3 days, $80 \%$ RE was achieved, which steadily increased until stabilising at $90 \%$ at day 21 . The OL was step increased to $c a$ $50 \mathrm{~g} \mathrm{~h}^{-1} \mathrm{~m}^{-3}$ of reactor (day 22) and $500 \mathrm{~g} \mathrm{~h}^{-1} \mathrm{~m}^{-3}$ of reactor (day 40) in order to test the VPB high concentration limit. Under such conditions (OL of $c a$ $50 \mathrm{~g} \mathrm{~h}^{-1} \mathrm{~m}^{-3}$ of reactor) the RE was further increased, stabilising at $95 \%$. When the OL was increased to ca $500 \mathrm{~g} \mathrm{~h}^{-1} \mathrm{~m}^{-3}$ of reactor, the RE was decreased significantly to around $20 \%$, thus suggesting that a high-limit concentration had been reached. During the high OL operation period, accumulation of SOLV was observed in the recirculation vessel, reaching a maximum of $1800 \mathrm{mg} \mathrm{dm}^{-3}$.

\subsection{MM optimisation}

As nutrient requirements contribute to the operational costs of VPB, a full design of experiments was carried out, aimed at the optimisation of the MM composition. No significant statistical difference on both parameters analysed, microbial specific growth rate and maximum biomass concentration, was observed on the experiments carried out. Such results indicate that the direct costs associated with MM composition could be significantly reduced by eliminating the metal supplement and reducing to one-tenth the initial concentration of the three main medium constituents: phosphate buffer, magnesium and ammonium salts.

\subsection{VPB operation at pilot-scale}

The laboratory-scale VPB was scaled up to a pilot-unit for in-situ implementation and operation. The design of the pilot-scale VPB took into consideration the data obtained during the laboratory-scale experiments, including the predominance of treatment at the lower VPB sections, which resulted in the increase of the diameter/height ratio at the pilot-scale VPB.

The VPB was firstly operated in a closed mode for 1 week, inoculated with biomass previously produced at laboratory-scale, and artificially feeding the carbon source to the liquid phase by the addition of known quantities of solvent (average SOLV concentration of $100 \mathrm{mg} \mathrm{dm}^{-3}$ ). A total of $50 \mathrm{dm}^{3}$ of concentrated specialised microbial culture was produced to use as inoculum to the pilot-scale VPB, an operation which was laborious to carry out. Since the inoculum concentration is a key-parameter when aiming at a successful start-up of biological treatment technologies, ${ }^{10}$ the development of methodologies for mass production of specialised microbial cultures would be advantageous.

The pilot-scale unit was operated in-situ $12 \mathrm{~h}_{\text {day }}{ }^{-1}$ and 5 days per week. Based on the laboratory-scale 


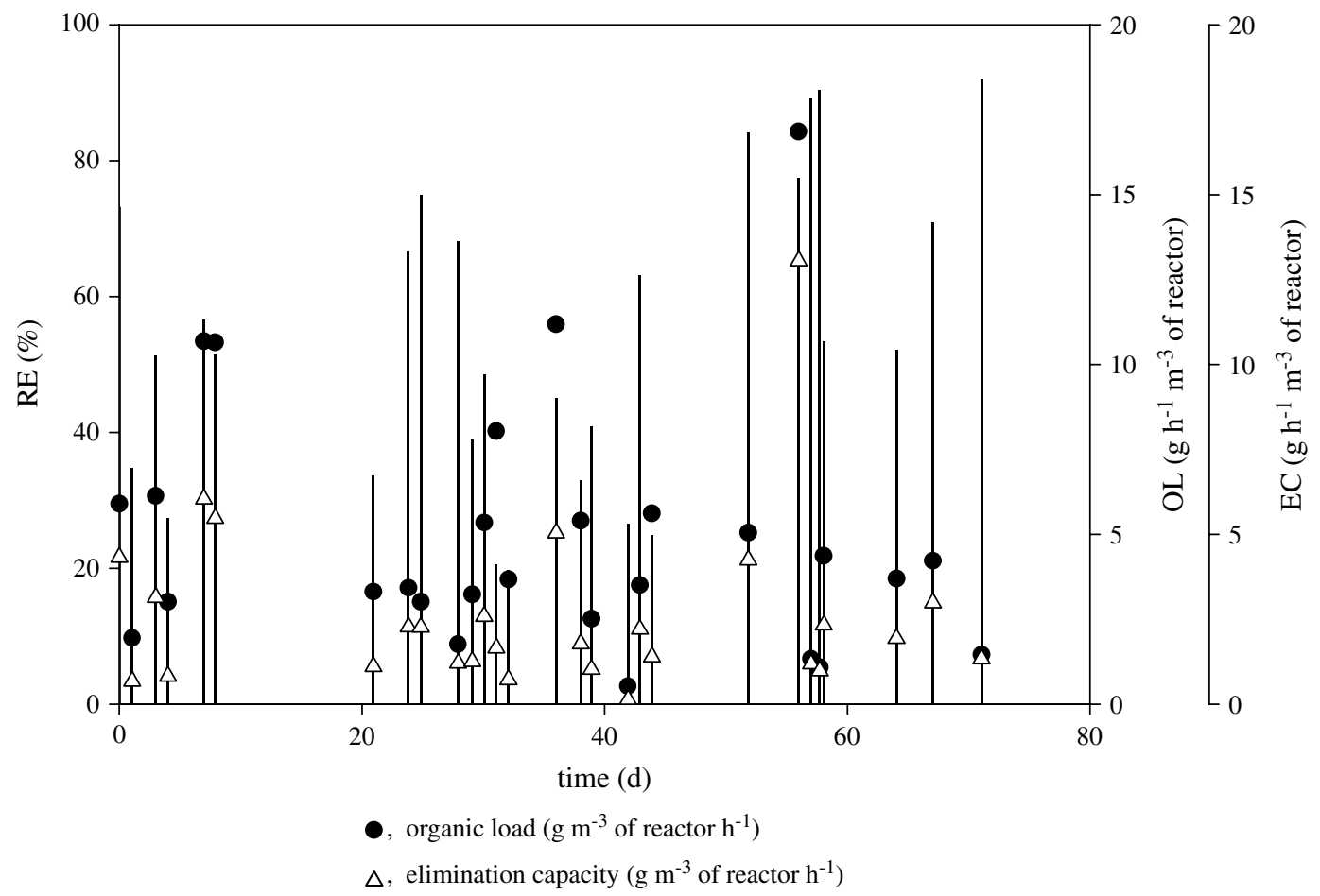

Figure 4. Removal efficiency (RE, \%, vertical bars) versus organic load $\left(\mathrm{g}^{-3}\right.$ of reactor $\mathrm{h}^{-1}$ ) and elimination capacity ( $\mathrm{g} \mathrm{m}^{-3}$ of reactor $\mathrm{h}^{-1}$ ) obtained during VPB operation in-situ at pilot-scale.

results, $M M$ was not recirculated through the filter bed during shutdown periods. Inoculation of the microbial culture enriched at laboratory-scale was successful, as the biomass was capable of carrying out the treatment with ca 50\% RE after a few days of operation (Fig 4). In comparison to the laboratory-scale investigations, the VPB was exposed to low OL operating regimes (average of $5 \mathrm{~g} \mathrm{~h}^{-1} \mathrm{~m}^{-3}$ of reactor).

After day 7, the industrial unit was shut down for 15 days. Due to the recent start-up, a maintenance feed was introduced to the VPB, aimed at maintaining active microbial cultures in the reactor. Such maintenance feed consisted of pure SOLV fed to the recirculation reactor at $c a 10 \mathrm{gh}^{-1}$. The use of a maintenance feed has proved to be a feasible solution for reducing downtime in biological treatment technologies exposed to starvation periods. ${ }^{19,20}$ At day 18 , the VPB was exposed to the OL observed on day $7\left(10 \mathrm{~g} \mathrm{~h}^{-1} \mathrm{~m}^{-3}\right.$ of reactor) and similar RE were achieved, suggesting that the maintenance feed was a valuable tool for reducing downtime. On day 43 , the VPB was exposed to another week's starvation period and again the use of a maintenance feed may have allowed for the recovery observed after re-starting the operation.

Generally, and when compared with the laboratory studies, the VPB was exposed to low OL. From day 18, almost all the gas outlet concentrations were below the discharge limit of $150 \mathrm{mg} \mathrm{C} \mathrm{Nm}^{-3}$ introduced on $31 \mathrm{st}$ August 2001 by a new piece of legislation (Portaria $n .{ }^{\circ}$ 242/2001). Legal requirements recently introduced will force the adoption by industries of action plans aimed at the reduction of the gaseous emission rates $\left(\mathrm{g} \mathrm{h}^{-1}\right)$. Actions to be taken to implement such requirements may include the reduction of the total flow generated, which, in its turn, will result in the concentration of the pollutant emitted. Since the treatment of concentrated gaseous emissions is known to be a limitation when considering VPB application, further research under such treatment scenarios should follow, aimed at the maintenance of VPB as Best Available Technology.

\section{CONCLUSIONS}

The conclusions of this work are as follows:

(1) Microbial cultures were successfully enriched from soil samples. At laboratory-scale, a VPB was exposed to a gaseous emission containing pollutants typical of a paint and varnish plant and showed removal efficiencies higher than $90 \%$ when exposed to OL of $c a 50 \mathrm{~g} \mathrm{~h}^{-1} \mathrm{~m}^{-3}$ of reactor. MM composition was optimised, thus reducing the operational costs at pilot-scale.

(2) After a long starvation period, the introduction of a highly concentrated inocula of the enriched microbial culture was proven to be beneficial to the recovery of the treatment capacity. However, as shown during pilot-scale start-up, the mass production of microbial cultures is difficult to carry out. Investigations into a methodology that allows for an easy process for mass production of biomass should follow.

(3) The VPB was successfully scaled-up and operated in-situ. A maintenance feed was shown to be a useful tool for VPB pilot-scale operation when exposed to shutdown periods. Outlet 
concentrations were compliant with current legal demands.

(4) VPBs were shown to be robust, being able to respond actively to dynamic treatment scenarios, particularly night and weekend shutdown periods.

\section{ACKNOWLEDGMENTS}

The authors would like to thank the support from Agência de Inovação SA and AGROF and financial support from ICPME I9Ar research project P0065. R Ferreira Jorge would like to thank financial support from Fundação para a Ciência e a Tecnologia (BPD/6977/2001). The authors would like to thank technical support from J Araújo and Carmo during the operation of the VPB at laboratory-scale.

\section{REFERENCES}

1 BREF, http://eippcb.jrc.es/pages/FActivities.htm (Large Volume Organic Chemicals, BREF 02.02).

2 Stewart WC, Barton TA and Thom RR, High VOC loadings in multiple bed biofilters: petroleum and industrial applications. Environ Prog 20:207-211 (2001).

3 Deshusses MA, Hamer G and Dunn IJ, Behaviour of biofilters for waste air treatment. 2. Experimental evaluation of a dynamic model. Environ Sci Technol 29:1059-1068 (1995).

4 Kirchner K, Wagner S and Rhem H-J, Removal of organic air pollutants from exhaust gases in the trickle-bed bioreactor. Effect of oxygen. Appl Microbiol Biotechnol 45:415-419 (1996).

5 Baltzis BC, Mpanias CJ and Bhattacharya S, Modeling the removal of VOC mixtures in biotrickling filters. Biotechnol Bioeng 72:389-401 (2001).

$6 \mathrm{Lu}$ C, Lin M-R and Wey I, Removal of pentane and styrene mixtures from waste gases by a trickle-bed air biofilter. $\mathcal{F}$ Chem Technol Biotechnol 76:820-826 (2001).

7 Paca J, Koutsky B, Maryska M and Halecky M, Styrene degradation along the bed height of perlite biofilter. $\mathcal{F}$ Chem Technol Biotechnol 76:873-878 (2001).

8 Splendiani A, Moreira de Sa JAGC, Ferreira Jorge RM, Nicolella C, Livingston AG, Hughes K and Cook S, Development of an extractive membrane bioreactor for degradation of 3-chloro-4-methylaniline in an industrially produced wastewater; from bench to pilot scale. Environ Prog 19:18-27 (2000).

9 Bastos F, Bessa J, Pacheco C, De Marco P, Castro P, Silva M and Ferreira Jorge R, Enrichment of microbial cultures able to degrade 1,3-dichloro-2-propanol: a comparison between batch and continuous methods. Biodegradation 13:211-220 (2002).

10 Alexander M, Biodegradation and Bioremediation, 2nd edn. Academic Press, San Diego (1999).

11 Oh YS and Bartha R, Design and performance of a trickling air biofilter for chlorobenzene and $o$-dichlorobenzene vapors. Appl Environ Microbiol 60:2717-2722 (1994).

12 Baltzis BC, Mpanias CJ and Bhattacharya S, Modeling the removal of VOC mixtures in biotrickling filters. Biotechnol Bioeng 72:389-401 (2001).

13 Li G-W, Hu H-Y, Hao J-M and Zhang H-Q, Biological treatment characteristics of benzene and toluene in a biofilter packed with cylindrical activated carbon. Water Sci Technol 46:51-56 (2002).

14 Deshusses MA, Hamer G and Dunn IJ, Transient-state behaviour of a biofilter removing mixtures of vapors of MEK and MIKB from air. Biotechnol Bioeng 49:587-598 (1996).

15 Ergas SJ, Shumway L, Fitch MW and Neemann JJ, Membrane process for biological treatment of contaminated gas streams. Biotechnol Bioeng 63:431-441 (1999).

16 Shareefdeen $Z$ and Baltzis BC, Biofiltration of toluene vapor under steady-state and transient conditions: theory and experimental results. Chem Eng Sci 49:4347-4360 (1994).

17 Togna AP and Singh M, Biological vapor-phase treatment using biofilter and biotrickling filter reactors: practical operating regimes. Environ Prog 13:84-94 (1994).

18 Hekmat D, Linn A, Stephan M and Vortmeyer D, Biodegradation dynamics of aromatic compounds from waste air in a trickle-bed reactor. Appl Microbiol Biotechnol 48:129-134 (1997).

19 Ferreira Jorge RM and Livingston AG, Microbial dynamics in an extractive membrane bioreactor exposed to an alternating sequence of organic compounds. Biotechnol Bioeng 70:313-322 (2000).

20 Ferreira Jorge RM and Livingston AG, Biological treatment of an alternating source of organic compounds in a single tube extractive membrane bioreactor. I Chem Technol Biotechnol 75:1174-1182 (2000).

21 Yeom S-H and Daugulis AJ, Development of a novel bioreactor system for treatment of gaseous benzene. Biotechnol Bioeng 72:156-165 (2001).

22 Song J and Kinney KA, Effect of a vapor-phase bioreactor operation on biomass accumulation, distribution, and activity: linking biofilm properties to bioreactor performance. Biotechnol Bioeng 68:508-516 (2000).

23 Bastos F, Castro PML and Ferreira Jorge RM, Biological treatment of a contaminated gaseous emission containing monochlorobenzene (in press).

24 Goodal JL, Thomas SM, Spain JC and Peretti SW, Operation of mixed culture immobilized cell reactors for the metabolism of meta- and para-nitrobenzoate by Comamonas sp JS46 and Comamonas sp JS47. Biotechnol Bioeng 59:21-27 (1998). 